\title{
Method of placer mining by directional well drilling
}

\author{
Viktor Bagazeev ${ }^{1}$, Niyaz Valiev ${ }^{1}$, Konstantin Kokarev ${ }^{1}$, and Vasiliy Startsev ${ }^{* 1}$ \\ ${ }^{1}$ Federal State Budgetary Educational Institution of Higher Education "Ural State Mining University" \\ Yekaterinburg, Russia
}

\begin{abstract}
The study aims at justifying the method for the development of placers by directed drilling of wells. A description is given of the opening of the site, the receding and oncoming scheme of the digging excavation, drilling and expansion of the wells, the main hydraulic unit with remote control. The physics-mechanical substantiation of technological parameters is given: hydro-jet erosion, the shape and size of the cleaning chambers, the adaptation of hydrotransport calculation methods. With jetting, the required flow rate and pressure of water to break rocks is based on the laws of soil mechanics. The parameters of the clearing space and the shape of the chambers are taken in accordance with the magnitude of the vault of natural equilibrium. As a determining factor in the calculation of gravity hydrotransport, the consistency of the pulp is adopted with observance of the condition necessary for the bearing capacity. To adapt the methodology for calculating the hydraulic lifting of pulp to the conditions of well development, the coefficient of dilution is taken as the main design parameter. Modeling of jetting jet in the laboratory conditions was carried out, dependences of decrease in axial pressure were obtained at removal of the face from the nozzle.
\end{abstract}

\section{Introduction}

A promising trend set to increase the gold reserves is to involve placer accumulations and deposits hard-to-reach by traditional technologies in the development using the method of hydraulic mining by horizontal directional well drilling (HDD). Horizontal directional drilling makes it possible to place a high-capacity hydromonitor barrel at the well bottom, to increase the productivity of hydraulic washing-out, to clean the placer bedrock, to exclude the impact of sediments on the well and the collapse of barren rocks (peats).

The research aims at justification of the method and technological parameters of hydraulic placer mining by means of directional well drilling on the basis of physical and mechanical properties of rocks.

The research focuses on the mechanisms of hydraulic washing-out, hydraulic transportation, and the stability of rock outcrops.

The justification of the method and its technological parameters is of crucial importance now when the placer reserves are being depleted while the mining depth is being increased.

${ }^{*}$ Corresponding author : Vasiliy.Startsev@m.ursmu.ru 
The implementation of the method will make it possible to work out unmined areas of deep depressions and bedrock cuts as well as placers and man-made massifs having a small volume of rock mass and a high gold content.

The scientific novelty of the study is protected by the patent as a method of hydraulic well drilling of useful minerals [1].

The leading developers of hydraulic well drilling technologies in Russia are academician V. Zh. Arens, professor N. I. Babichev, V. L. Kolibaba, A. V. Pankov, A. S. Khrulev, E. I. Cherney, D. N. Shpak . Problems of hydraulic well drilling are also solved in the works of V. P. Drobadenko, G. A. Nurok, N. G. Malukhin, V. F. Khnykin, S. S. Shavlovskiy, and others.

\section{Theory and experimental work}

The mining complex of hydraulic mining by horizontal directional well drilling includes (Fig. 1):

- drilling equipment: drilling rig, drilling tool set, equipment used to prepare, deliver, and reclaim drilling mud, control location systems;

- washing equipment: hydromonitor barrel, pump and pipes to supply water under high pressure;

- pulp lifting equipment: soil pump, hydraulic elevator, air lift.

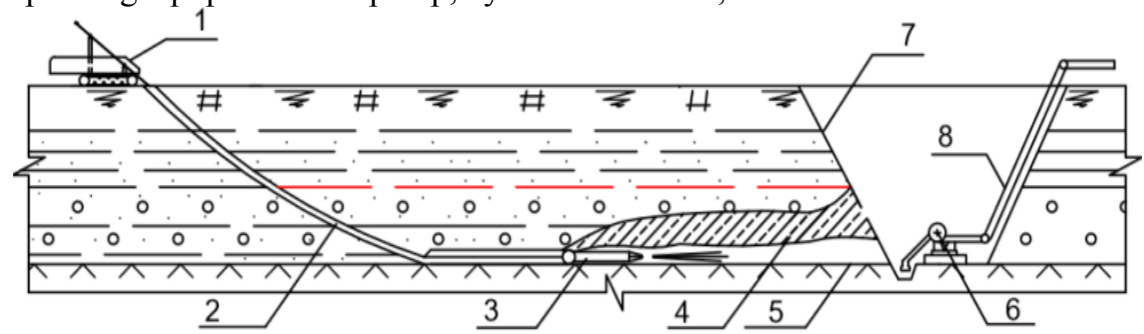

Fig. 1. Principal technological scheme of hydraulic mining by horizontal directional well drilling: 1 horizontal directional drilling rig; 2 - well; 3 - water monitor; 4 - well bottom; 5 - transportation section of a well ; 6 - soil pump or hydraulic elevator; 7 - working trench; 8 - pulp line

Production wells are assumed to be drilled by a typical horizontal directional drilling rig used to lay pipelines [2]. Taking into account the diameter of the hydromonitor barrel, wells are drilled in stages:

- drilling of a pioneer well having a diameter of up to $200 \mathrm{~mm}$ ( entering a massif at an angle of $28-30^{\circ}$ or up to $40^{\circ}$ );

- reverse washing-out of a pioneer well up to $400-450 \mathrm{~mm}$.

The well accommodates a pressure conduit ending with a hydromonitor barrel. The hydromonitor barrel connected with a pipeline by means of a ball joint or a pressure hose is supposed to be manipulated in the horizontal plane.

As the devices identical in design, a typical hydromonitor barrel with two nozzles used to wash out the rocks under water and a typical hydromonitor barrel GMD (ГМД) -250 used for opencast workings are considered to be the most appropriate ones. It is advantageous to use a remote control cable stretched along the pipeline.

The lifting equipment is typical and its choice is determined by the mining depth.

To determine the technological parameters, it is necessary to provide a special physical and mechanical justification of hydraulic washing-out and stopes formation as well as the adaptation of hydraulic transportation calculation methodologies.

The mechanism of hydraulic fracturing of clay rocks is outlined as follows: the rock mass is solid, isotropic and impermeable; the loading condition with an impinging water jet 
is quasistatic; the destructive load is applied to the area of a circle whose radius is somewhat smaller than the radius of a water jet; the load distribution is uniform. When the destruction takes place, the value of pressure $P_{\mathrm{p}}, \mathrm{MPa}$, is taken as calculated according to the Prandtl-Reisner formula [3]approximated for loamy rocks within the internal friction angle $\varphi=10-35^{\circ}$ by the expression:

where $c$ is the soil adhesion, MPa.

$$
P_{p}=c \cdot \operatorname{ctg} \varphi \cdot 0.00025 \cdot \varphi^{2.6}
$$

The destructive load corresponds to the head of the water jet at the well bottom $H_{\min }, \mathrm{m}$ :

$$
H_{\min }=K_{3} \frac{P_{p}}{2 g \cdot \rho}=55 \cdot P_{p}
$$

where $K_{3}=1.05-1.1$ is the safety factor;

$\mathrm{g}=9.81 \mathrm{~m} / \mathrm{s}^{2}$

$\rho=1.0 \mathrm{t} / \mathrm{m}^{3}$ is the water density.

The required amount of water [4]:

$$
q_{\mathrm{T}}=\frac{7.05 \sqrt{H \cdot E \cdot \rho}}{\left(f \cdot H-H_{\min }\right)}
$$

where $q_{\mathrm{T}}$ is the discharge of water, $\mathrm{m}^{3}$, having the head $H$, $\mathrm{m}$, to wash out $1 \mathrm{~m}^{3}$ of rocks;

$f$ is the coefficient of the relief of axial pressure of the water jet due to the increase in the distance from the well bottom to the nozzle $l$.

The analytical expression of the coefficient $f$ was derived on the basis of analogy with $\mathrm{S}$. S. Shavlovskiy's studies of the opencast workings [5] and the results of the axial pressure measurements under laboratory conditions (Fig. 2).

$$
f=\frac{P_{l}}{P_{0}}=\exp \cdot\left(-d_{n} \cdot l^{0.78} \cdot \sqrt{H}\right),
$$

where $P_{l}, P_{o}$ are the values of the axial pressure of the jet at a distance $l$ and in the immediate vicinity of the nozzle, $\mathrm{kPa}$;

$d_{\mathrm{n}}$ is the diameter of the nozzle of the hydromonitor barrel, $\mathrm{m}$;

$H$ is the water head in front of the nozzle, $m$

$l$ is the distance from the nozzle to the well bottom, $\mathrm{m}$.

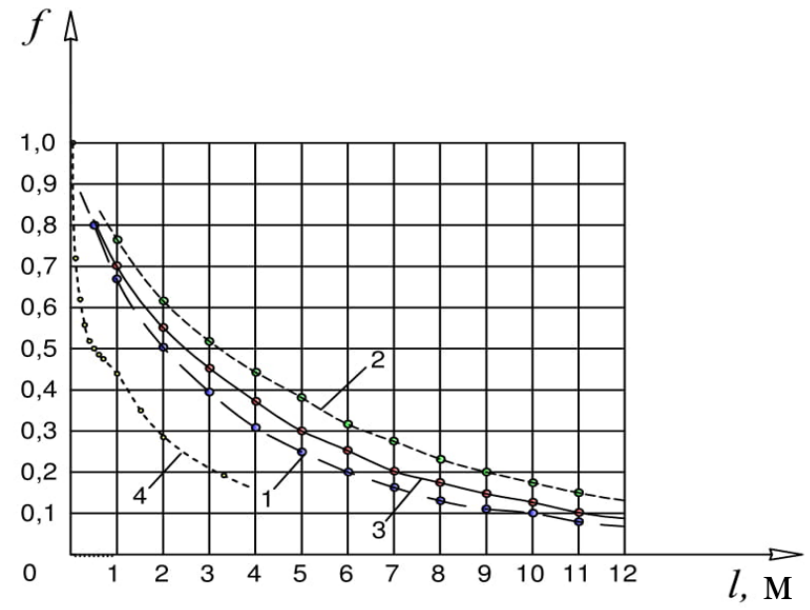

Fig. 2. Dependence of the coefficient of the relief of the axial pressure of the mediumpressure jet on the distance to the nozzle: 1, 2, and 3 are based on S.S. Shavlovskiy's measurement results, while [5], 4 are based on the model results;

$$
1-d_{\mathrm{H}} \sqrt{ } H=0.4 ; 2-d_{\mathrm{H}} \sqrt{ } H=0.28 ; 3-d_{\mathrm{H}} \sqrt{ } H=0.34 ; 4-d_{\mathrm{H}} \sqrt{ } H=0.0032
$$

The features which can be distinguished as specific to slushy gold-bearing placer mining are as follows: 
- the lack of a stable roof and a well- defined boundary line between the sands and peats;

- the presence of coarse clastic material in placer deposits;

- the possibility of the roof collapse.

At the same time, the parameters of the exposed stope (length, width, area) are not limited to the conditions of the required long-term stability. Under these conditions, the corresponding spatial shape of the stope washed out by a water jet will look like $1 / 2$ part of the spherical sector with its top at the nozzle of the hydraulic monitor placed in the well. In the plan a stope has the form of a sector.

In accordance with the hypothesis of the dome of natural equilibrium [6] and the formula of Borisov A. A.

$$
\left.L_{d}=(2.0 \div 3.0) h_{d}\right) L_{\text {пр }}=(2,0 \div 3,0) h_{\text {св }},
$$

where $L_{\mathrm{d}}, h_{\mathrm{d}}$ are the width and height of the dome of natural equilibrium, $\mathrm{m}$.

If the average value of the parabolic arch $h_{\mathrm{CB}}$ is taken to be equal to the thickness of the productive placer deposits $M, \mathrm{~m}$, the width of the stope $B_{\mathrm{K}}, \mathrm{m}$, appears to be as follows:

$$
B_{\mathrm{K}}=\frac{3}{2} M \text {. }
$$

In case of hydraulic placer mining, it is advisable to take the pulp consistency expressed as the solid to liquid ratio (T:Ж) as the determining factor for the calculation of the hydraulic transportation of rocks,. The solid to liquid ratio (T:Ж) is the amount of water, $\mathrm{m}^{3}$, per $1 \mathrm{~m}^{3}$ of the solid in the pulp. According to A. I. Kuprin's formula [7], the gravity flow of the pulp will have a sufficient load-bearing capacity at the ratio:

$$
\mathrm{T}: Ж \geq \frac{\rho_{\text {тв }}}{\rho_{\text {тв }}-\rho_{\text {п }}} \cdot \frac{\kappa_{\mathrm{T}} \cdot J}{f_{\text {л }}-J},
$$

where $\rho_{\mathrm{TB}}, \rho_{\mathrm{I}}$ are the densities of solid particles and the pulp, $\mathrm{t} / \mathrm{m}^{3}$;

$K_{\mathrm{T}}=0.07-0.14$ is the coefficient of the energy transfer to the flow of liquid;

$f_{\mathrm{n}}=0.34-0.47$ is the coefficient of friction of a solid moving along the chute (gutter).

On the basis of generalization of theoretical propositions and experimental studies, B. E. Fridman [8] developed a methodology for the calculation of the pressurized hydraulic transportation by a hydraulic elevator. In the methodology the main design parameter is the pulp density.

This technique has been adopted to the hydraulic well drilling. It takes the coefficient of the pulp dilution in the hydraulic elevator [9] as its main design parameter:

$$
\mathrm{K}_{\mathrm{p}}=\frac{n_{1}+1}{n_{2}-n_{1}},
$$

where $n_{1}, n_{2}$ is the liquid to solid ratio in the feed pulp (before the hoist of the hydraulic elevator) and in the pulp after the hoist of the hydraulic elevator.

\section{Results and generalization}

The research results in the justification of the method of placer mining by directional well drilling which excludes the surface damage.

Analytical expressions of technological development parameters are derived from physical and mechanical properties of placer rocks. The parameters of the washing-out and the stopes are based on the laws of loamy rock mechanics. The methods for the calculation of gravity and pressurized hydraulic transport are adapted to the conditions of hydraulic well drilling. 


\section{Conclusion}

The implementation of the method opens bright prospects for the development of unmined small placers and accumulations of alluvial gold in man-made mineral formations.

\section{References}

1. V. A. Startsev, N. G. Valiev, V. K. Bagazeev, I. L. Zdorovets, D. I. Simisinov, Patent of the Russian Federation No. 2640611, МПК 21C 45/00 (2006.01), E21C 41/16 (2006.01), E21C 41/26 (2006.01) Method of hydraulic well drilling of mineral resources / FSBEI HE USMU. No. 2016121266, applied 05/30/2016; published 01/10/2018. Bul. 1.

2. Method of horizontal directional drilling in subsurface utility engineering. STO NOSTROY-15. 124 p. (2011).

3. N. A. Tsytovich, Soil mechanics. Moscow: Vysshaya Shkola, 288p. (1984).

4. V. K. Bagazeev, N. G. Valiev, D. I. Simisinov, Physical and mechanical justification of hydraulic fracturing of rocks in the process of hydraulic well drilling. Gornyi zhurnal. 12. (2015).

5. S. S. Shavlovskiy, Fundamentals of jet dynamics in the process of rock mass destruction. Moscow: Nauka, 173 p. (1979).

6. M. V. Rylnikova, O. V. Zoteev, Geomechanics. - Closed Joint-Stock Company "Publishing House" Ore and Metals ", (2003).

7. A. I. Kuprin, Gravity pipeline transportation. Moscow: Nedra, 244 p. (1980).

8. B. E. Fridman, Hydraulic elevators. Moscow: Matgiz, (1960).

9. V. K. Bagazeev, V. I. Shok, Justification of the parameters for the selection of a hydraulic elevator for the development of alluvial deposits, Izvestiya vysshikh uchebnykh zavedeniy. Gornyi zhurnal. 8. P. 4-10. (2016). 